\title{
HAVING A GO AT SPINAL MUSCULAR ATROPHY WITH SPINRAZA
}

\author{
BALAJI O, AMITA D, SEREEN RT, NAVIN AP*
}

Department of Pharmacology, Kasturba Medical College, Manipal, Karnataka, India. Email: navin903@gmail.com

Received: 05 February 2017, Revised and Accepted: 16 March 2017

\begin{abstract}
Spinal muscular atrophy (SMA), a neurological condition which is genetically mediated is the second most common infantile disease causing morbidity and mortality next to cystic fibrosis. It is of five different types with each type having different severity outcomes. For almost three decades, only supportive measures were advocated in the treatment of SMA. Recently, Biogen's Spinraza came out as the first disease modifying therapy to treat infantile as well as adult SMA. This review throws light on the pharmacological aspects of the drug; its approval by Food and Drug Administration and various completed clinical trials as well ongoing clinical trials.
\end{abstract}

Keywords: Spinraza, Spinal muscualr atrophy, Antisense oligonucleotide, Adverse effects, Endear trial.

(C) 2017 The Authors. Published by Innovare Academic Sciences Pvt Ltd. This is an open access article under the CC BY license (http://creativecommons. org/licenses/by/4. 0/) DOI: http://dx.doi.org/10.22159/ajpcr.2017.v10i6.17502

\section{INTRODUCTION}

Spinal muscular atrophy (SMA), a rare autosomal recessive disorder, causes debilitating infantile illness ultimately making it the leading genetic cause of infantile death. It is very rare with an incidence of 1 in 100000. SMA 1 gene is associated with the pathogenesis of the disease, and this discovery had opened the gates for experimentation of new drugs. Recently, in December 2016, Food and Drug Administration (FDA) approved Spinraza (Nusinersin) for the treatment of both adult and Paediatric SMA.

\section{SMA}

The first description of SMA dates back to $19^{\text {th }}$ century, described by Werding and Hoffman, when they illustrated cases of motor nerve paralysis along with muscle atrophy. Later autopsy revealed severe loss of neurons in anterior horn of spinal cord along with atrophic changes in the ventral root of the spinal cord, so-called pathological hallmarks of SMA [1].

SMA is genetic disorder usually associated with deletions of SMA protein in $5 q$ chromosome, so-called $5 q$ SMA or proximal SMA. It accounts for $95 \%$ of present cases reported leaving behind other mutations causing SMA with heterogeneous presentations. SMN is the second most common genetic disorder of infancy next only to cystic fibrosis with selective damage to spinal neurons causing various degrees of muscle wasting mainly starting with lower limbs and also associated with other systemic manifestations. Clinical manifestations include breathing difficulties, constipation, weight loss, Gastroesophageal dysfunction, cardiac abnormalities due to autonomic instability, congenital heart defects, muscle wasting, loss of deep tendon reflexes and also bulbar and brainstem involvement. SMA is divided into five types and characteristics are summarized in Table 1. This can be because of SMN gene mutation with deletions in exon 7 or 8 . Sometimes, it is due to homozygous type having deletion of both SMN 1 Gene and having two copies of SMN 2 gene. It can be heterozygous type with One SMN 1 gene and having mutations in other copy of SMN 1 gene. For many years, there was no proper disease modifying therapy to treat SMA. Only supportive measures were used such as respiratory support, nutritional support, physical exercises, and end of life care. Various therapies including gene therapy, antisense oligonucleotides, small molecules therapy have been tried [1]

Of this Spinraza, the antisense oligonucleotide was successful and was approved by FDA on 23.12.2016 and has also been given an orphan drug status. The drug was given priority review and fast-track approval status and also FDA gave rare pediatric drug review voucher to BIOGEN company which they could use for any other product review in future. Spinraza is said to be the eight drug to receive rare pediatric review voucher from FDA [2]

\section{SPINRAZA}

It contains Nusinersin, an antisense oligonucleotide modified with phosphate linkages and hydroxyl groups of ribofuranosyl rings being replaced with phosphorothioate linkage and methoxyethyl groups, respectively. SpinRaza, with a structural formula $\mathrm{R}=\mathrm{OCH}_{2} \mathrm{CH}_{2} \mathrm{OCH}_{3}$, is a sterile, colorless solution supplied in single glass vial for intrathecal use without addition of any preservatives. The molecular formula is $\mathrm{C}_{234} \mathrm{H}_{323} \mathrm{~N}_{61} \mathrm{O}_{128} \mathrm{P}_{17} \mathrm{~S}_{17} \mathrm{NA}_{17}$ with a molecular weight of 7501.0 daltons. $1 \mathrm{ml}$ of Spinraza contains $0.22 \mathrm{mg}$ of potassium chloride, $0.21 \mathrm{mg}$ of calcium chloride, $0.16 \mathrm{mg}$ of magnesium chloride, $8.22 \mathrm{mg}$ of sodium chloride, $0.10 \mathrm{mg}$ of sodium phosphate, and $0.05 \mathrm{mg}$ of sodium phosphate monobasic dihydrate. It as a PH OF 7.2 [3].

\section{MECHANISM OF ACTION}

It is known with evidence that deficiency of SMN protein is mainly via mutations in chromosome $5 \mathrm{q}$. It is shown that SPINRAZA increases inclusion of exon 7 in SMN2 messenger ribonucleic acid transcripts. Henceforth, it results in production of full-length SMN protein [3].

\section{PHAMACOKINETICS}

It is distributed from the CSF to target central nervous system tissues when given intrathecally. Trough plasma levels were low when compared to trough CSF levels. Median $\mathrm{T}$ max ranges from 1.7 to $6.0 \mathrm{hrs}$. It is also distributed to liver, kidney, and skeletal muscles. It is metabolized by exonucleases mediated hydrolysis. It is neither an inhibitor nor an inducer of CYP450 enzymes. Mean elimination halflives of Spinraza in CSF and plasma are found to be 135-177 days and 63-87 days, respectively. The primary mode of elimination is via the kidneys with only $0.5 \%$ of administered dose excreted in urine $[3,4]$.

\section{DOSAGE AND ADMINISTATION}

Recommended dosage is $12 \mathrm{mg}(5 \mathrm{ml})$ per administration. Treatment is initiated with 4 loading dose with first three loading doses administered at intervals of 14 days followed by $4^{\text {th }}$ dose 30 days after the $3^{\text {rd }}$ dose. Maintenance dose is usually once in 4 months. Usually, it is kept at $25^{\circ} \mathrm{C}$ at the time of administration and followed by refrigeration when not 
Table 1: Types and characteristics of SMA

\begin{tabular}{|c|c|c|c|}
\hline Types of SMA & Onset & Life expectancy & Clinical manifestations \\
\hline Type 0 & In utero, very severe & 1 week after birth & $\begin{array}{l}\text { Failure to swallow and breathe, facial diplegia and joint } \\
\text { contractures }\end{array}$ \\
\hline $\begin{array}{l}\text { Type } 1 \text { (Werdnig-Hoffman } \\
\text { disease) }\end{array}$ & $\begin{array}{l}4-5 \text { months, } 50 \% \\
\text { patients }\end{array}$ & 2 years of life & $\begin{array}{l}\text { Floppy infant syndrome along with usual clinical } \\
\text { manifestations of SMA }\end{array}$ \\
\hline Type 2 (Dubowitz disease) & 7-18 months & 2-40 years & Delay of gross motor skills \\
\hline $\begin{array}{l}\text { Type } 3 \text { (Kugellberg-Welander } \\
\text { disease) }\end{array}$ & 18 months - 3 years & $\begin{array}{l}\text { Life expectancy-general } \\
\text { population }\end{array}$ & Muscle hypotonia and wasting \\
\hline
\end{tabular}

SMA: Spinal muscular atrophy

used. Discoloration of vial and particulate matter prohibits the use of the drug. Spinraza should be administered within 4 hrs once taken out of the vial. Proper sedation and ultrasound imaging techniques are used to administer drug intrathecally. Before administering the drug, $5 \mathrm{ml}$ of cerebrospinal fluid should be removed, and drug is administered over 2-3 minutes as intrathecal bolus dose using spinal needle. Avoid inflammatory or infectious skin sites [3]

\section{WARNING AND PRECAUTIONS}

In a clinical study, $11 \%$ of 56 patients developed fall in platelet counts below the lower limit of normal compared to none in sham control. No patient had sustained platelet count drop despite continued drug exposure. Hence, because of thrombocytopenia there is a risk of bleeding, so proper monitoring of coagulation profile and platelet counts before and after Spinraza is essential.

In a clinical study among patient treated for 7 months, elevation in urine protein was found among $33 \%$ treated with SpinRaza compared to $20 \%$ of sham control. In those treated for 34 months $69 \%$ had elevated protein. No elevated of blood urea nitrogen, creatine was noted. Hence, since Spinraza causes elevation of protein, spot urine protein testing is of prudent importance so as to prevent the patient from acute renal toxicity [3].

\section{ADVERSE EFFECTS}

Many adverse effects caused by Spinraza are included in (Table 2) Respiratory complications include pneumonia, bronchiolitis, syncytial viral bronchiolitis, pharyngitis, rhinitis, tracheitis, and nasopharyngitis. Skin rashes were also noted in few patients, spontaneously resolved. Other common adverse effects noted were headache, back pain, postlumbar puncture syndrome [5]. Immunogenicity of Spinraza reveals production of anti-Spinraza antibodies in few patients, but data are insufficient to evaluate the effect of antibodies on clinical response [3]

\section{SPINRAZA IN SPECIFIC POPULATION}

1. No teratogenicity was observed in animal studies.

2. In animal models, no embryonal damage or organogenesis was affected.

3. In juvenile animal toxicity data in monkeys reveals Spinraza causes neuronal vacuolation at hippocampus and transient defects in lower spinal reflexes at high doses. Furthermore, learning and memory deficits were observed.

4. SMA is disease of adult and children, so no geriatric exposure to this drug [3].

\section{CLINICAL TRIALS IN INFANTILE- ONSET SMA}

ENDEAR, a multicenter randomized double-blind study with 121 infants $<7$ months was started, and an interim analysis was done [6]. Scoring was done with Hammersmith Infant Neurologic Exam and the Children's Hospital of Philadelphia infant test of neuromuscular disorders [7]. A minimum score of 2 and maximum
Table 2: In controlled study in infants with SMA

\begin{tabular}{lll}
\hline Adverse effects & $\begin{array}{l}\text { Spinraza 12 MG } \\
\text { (infants with } \\
\text { SMA) (\%) }\end{array}$ & $\begin{array}{l}\text { Control } \\
\text { patients (\%) }\end{array}$ \\
\hline Respiratory infections-lower & 43 & 29 \\
Respiratory infections-upper & 39 & 34 \\
Constipation & 30 & 22 \\
Aspiration & 5 & 2 \\
Scoliosis & 5 & 2 \\
Ear infections & 5 & 2 \\
Congestion of URT & 6 & 2 \\
Teething & 14 & 7 \\
\hline
\end{tabular}

SMA: Spinal muscular atrophy

Table 3: Chop-intend results

\begin{tabular}{lll}
\hline End point & $\begin{array}{l}\text { Spinraza } \\
\text { treated (\%) }\end{array}$ & $\begin{array}{l}\text { Sham } \\
\text { control (\%) }\end{array}$ \\
\hline $\begin{array}{l}\text { Motor milestone } \\
\begin{array}{l}\text { Chop-intend improvement from } \\
\text { baseline }\end{array}\end{array}$ & 40 (improved) & 0 \\
Chop-intend worsening & 43 & 3 \\
\hline
\end{tabular}

of 26 was given and those who have scores $>2$ were categorized as treatment responders. Responder also needs to fulfill the criteria of improvement in motor milestones. Results of interim analysis are shown in Table 3. These were supported by open-label trials in infants aged from 30 to 15 years in symptomatic SMA and from 8 to 42 days in case of asymptomatic SMA at the time of the first dose. The patients could achieve milestones, some maintained motor milestones at ages and some survived to ages. The overall findings of the controlled trial in infantile-onset SMA and the open-label uncontrolled trials support the effectiveness of SpinRaza across the range of SMA patients and appear to support the early initiation of treatment with SpinRaza.

\section{SUMMARY OF CLINICAL TRIALS FOR SPINRAZA [1]}

- CHERISH (NCT02292537)

Phase 3 - randomized, sham-controlled trial in children with SMA. Positive Interim Results were obtained. The study is closed.

Supporting open-label studies

- $\quad$ SHINE (NCT02594124)

Phase 3 - open-label extension for participants in ENDEAR and CHERISH studies. On-going and recruiting participants.

- EMBRACE (NCT02462759)

Phase 2 - open-label, multi-dose trial in infants and children who did not qualify for ENDEAR or CHERISH. On-going.

- NURTURE (NCT02386553)

Phase 2 - open-label study in genetically diagnosed presymptomatic infants with SMA on-going. 
- $\quad$ CS3A (NCT01839656)

Phase 2 - open-label, multi-dose trial in infants with SMA to assess tolerability and pharmacokinetics. Completed

- CS12 (NCT02052791)

Phase 2 - open-label safety and tolerability study in patients with SMA who previously participated in the CS2 or CS10 studies. Completed

- $\quad$ CS10 (NCT01780246)

Phase 1 - open-label safety and tolerability study in patients with SMA who previously participated in the CS1 study. Completed

- $\quad$ CS2 (NCT01703988)

Phase 1 - open-label safety, tolerability and dose-range finding study of multiple doses in patient with SMA. Completed

- CS1 (NCT01494701)

Phase 1 - open-label safety, tolerability, and dose-range finding study in patients with SMA. Completed

\section{CONCLUSION}

Spinraza being a blockbuster drug in the treatment of SMA and with pride that it is the only drug approved for adult as well as Paediatric SMA makes it very unique. More clinical trials are needed to prove the safety and efficacy of this drug and also to look for long-term outcomes in the treatment of SMA.

\section{REFERENCES}

1. Faravelli I, Nizzardo M, Comi GP, Corti S. Spinal muscular atrophy - Recent therapeutic advances for an old challenge. Nat Rev Neurol 2015;11(6):351-9.

2. U.S. FDA Approves Biogen's SPINRAZATM (Nusinersen), the First Treatment for Spinal Muscular Atrophy [News release]. Boston, MA: Biogen; December 23; 2016. Available from: http://www.media. biogen. $\mathrm{com} / \mathrm{press}$-release/neurodegenerative-diseases/us-fda-approves-biogensspinraza-nusinersen-first-treatment. [Last accessed on 2016 Dec 23].

3. Biogen. SPINRAZA. Prescribing Information. Cambridge, MA: Biogen; December; 2016.

4. Chiriboga CA, Swoboda KJ, Darras BT, Iannaccone ST, Montes J, De Vivo DC, etal. Results from a phase 1 study of nusinersen(ISIS-SMN(Rx)) in children with spinal muscular atrophy. Neurology 2016;86(10):890-7.

5. Haché M, Swoboda KJ, Sethna N, Farrow-Gillespie A, Khandji A, Xia S, et al. Intrathecal injections in children with spinal muscular atrophy: Nusinersen clinical trial experience. J Child Neurol 2016;31(7):899-906.

6. Kuntz N, Farwell W, Zhong ZJ, Sun P, Gheuens S, Schneider E, et al. Nusinersen treatment of infantile-onset spinal muscular atrophy (SMA): Study design and initial interim efficacy and safety findings from the phase 3 ENDEAR study. World Muscle Society Meeting, Granada Spain, October; 2016.

7. Glanzman AM, Mazzone E, Main M, Pelliccioni M, Wood J, Swoboda KJ, et al. The Children's Hospital of Philadelphia Infant test of neuromuscular disorders (CHOP INTEND): Test development and reliability. Neuromuscul Disord 2010;20(3):155-61. 